\title{
Factors Affecting Micro and Small Enterprises in Accessing Credit Facilities: A Study in Gesuba Town, Wolaita Zone, Southern Nation Nationalities Peoples Regional State, Ethiopia
}

\author{
Merihun Marchu Haile \\ Department of Management, College of Business and Economics, New Global Vision College Awassa Campus, \\ Southern Ethiopia.
}

\begin{abstract}
In developing countries, micro and small enterprises (MSEs) have a vibrant role and serve as engines through which the growth objectives of developing countries can be achieved. The MSE sector has been instrumental in bringing about economic transition by providing goods and services, which are of adequate quality and are reasonably priced, to a large number of people, and by effectively using the skills and talents of a large number of people without requiring high level training, large sums of capital or complicated technology. However access to finance remains to be a major problem hampering MSEs from playing their productive role in the economy. In developing countries, micro and small enterprises (MSEs) have a vibrant role and serve as engines through which the growth objectives of developing countries can be achieved. Interviews and semi structured questionnaire have been used as a tool to gather the information. Binary logistic regression and descriptive analysis were used to identify major factors affecting access to credit from formal financial institutions and test the hypotheses. The result of the study revealed that age of operator, educational level, and possession of fixed asset, employment size, lending procedure and loan repayment period are significant factors that affect MSEs' access to credit. MSEs run by operators of greater than 40 years of age, that have reached TVET/College and above, which possess fixed asset, with greater than 6 employees are more likely to access credit from formal financial institutions than MSEs run by operators of less than 40 years of age, with no formal education, do not have fixed asset and with less than 6 employees. In addition, MSEs run by operators who have negative attitude towards lending procedure and loan repayment period of formal financial institutions are less likely to access credit than those which do not. Considering the role MSEs in employment generation, income creation and poverty alleviation, all stakeholders (government and non-governmental institutions) have responsibilities to facilitate sufficient access of finance for MSEs.
\end{abstract}

Keywords: Access, Micro \&Small Enterprise, Credit Facilities, Education, Fixed asset, lending procedue DOI: $10.7176 / \mathrm{DCS} / 10-11-01$

Publication date: November $30^{\text {th }} 2020$

\section{INTRODUCTION}

\subsection{Background of the study}

It has long been recognized that in developing countries, micro and small enterprises (MSEs) have a vibrant role and serve as engines through which the growth objectives of developing countries can be achieved. MSEs by virtue of their size, capital investment and their capacity to generate greater employment have demonstrated their powerful propellant outcome for rapid economic growth in developing countries (ILO, 2008; Lara and Simeon, 2009). MSEs are described as efficient fruitful job creator, the seed of big businesses and the fuel of national economic engine (Abor \& Quartey, 2010). Cobbold et al. (2008) also suggested that MSEs are particularly important in supporting economic growth and livelihoods in developing countries. On top of this, micro and small enterprises are a crucial resource for the development of developing countries, not only for the contribution that it makes to poverty alleviation and job creation but also the sector is a base for entrepreneurial endeavor and the potential for new business development.

Molhotra et al. (2006) Wattanapruttipaisan (2003) and their co-authors described that MSEs play a crucial role in developmental goals such as in improving living standard, distributing income fairly among low level and high level group, reducing unemployment rate, promoting linkages among various economic sectors, easy to begin and expand, labor intensive, require small capital, low technology, little know -how and facilitates import and export transactions among countries. Due to this merit, the sector is receiving due attention of policy makers and development practitioners. Furthermore, MSEs serve as a bridge to reach at the technically advanced medium and large enterprises. In Ethiopia, MSEs Sector is the second largest employment-generating sector next to agriculture (CSA, 2005). According to CSA (2005) this sectors contributes 3.5\% of GDP, 34\% of the industrial sector's contribution and 51\% of the manufacturing sector contribution to the GDP of the year 2002. To that end in recent years the Ethiopian government has given special emphasis to the growth and development of Small and Micro Enterprises and they are now become the lifeblood of the Ethiopian economy. This is especially true as most graduates, learning institutions as well as policy makers are beginning to accept the fact 
that the larger organizations and government offices cannot provide all the needed jobs, but would have to be complemented by the MSEs.

The sector is also known in bringing economic transition by effectively using skills of people without requesting high level of training and high-tech technologies (Habtamu et al, 2013). As a result of it, they are recognized as a real engine of economic growth (Carrier, 1994; Mulharn, 1995). According to the MSEs development strategy of Ethiopia, the main objectives of SME's are: (I) to create job opportunities for the nation, to enhance the economic growth of the people and to reduce poverty and fair distribution of wealth. (II) Competitive and continual economic growth for the country and (III) improve the lively hood of the enterprise itself. In spite of the enormous importance of the micro, small and medium enterprises (MSME) sector to the national economy with regards to job creation and the alleviation of abject poverty, the sector is facing financial challenges, which hindered its role in the economy. Accessing finance is a make-or-break issue for large number micro and small enterprises (MSEs) in the developing world. Although, MSEs are major contributors to the gross domestic product (GDP) and employment in economies around the world, their financial needs are underserved, which holds back their growth. Where financing is available, it is usually out of reach because of short payback periods and excessive collateral requirements.

In order to fulfill their very purpose, MSEs need access to finance to carry out their business operation and expansion. An effective SME's financing provide opportunities for them, to meet their financial requirements and to achieve their intended target. Lack of finance for MSEs is not only hindering their expansion but also the growth of the nation's economy. Small and Micro Enterprises (MSEs) are commonly believed to have very limited access to credit facilities and other financial support services provided by financial institutions. This is because, these MSEs cannot provide the necessary collateral demanded by the financial institutions and financial institutions find it difficult to recover the high cost involved in dealing with small firms (Gebrehiwot and wolday, 2006). Finance is necessary to help MSEs to set up and expand their operations, build up new products, and invest in new staff or production facilities (WorldBank, 2008). Availability of finance determines the capacity of an enterprise in a number of ways, especially in choice of technology, access to markets, and access to essential resources which in turn significantly influence the viability and success of a business. Securing capital for business start-up or business operation is one of the major obstacles of every entrepreneur, particularly those in the MSE sector (Solomon, 2009).

Access to financing is recognized as the leading barrier to small businesses growth in Ethiopia, alike most other developing and under-developed countries. Small businesses, in most cases, manage to start a business with resources from informal sector, but find it extremely difficult to survive and expand without further financial assist from the institutional lenders (Fetene, 2010). The formal financial institutions in Ethiopia have not been able to meet the credit needs of the MSEs. Since there is high interest rate and collateral requirement, most MSEs have been forced to use the informal institutions for credit. The main sources of startup and expansion finance or funds for most MSEs in Ethiopia are personal savings followed by iqub/idir, family and friends/relatives. Nevertheless, the supply of credit from the informal institutions is often so constrained to meet the credit needs of the MSEs (Admasu, 2012).

Although significant number of researches in Ethiopia have identified finance as one of the main factors that affect success, performance and growth of MSEs (Admasu, 2012; Fetene,2010;Gedam, 2010), there is little empirical evidence on factors affecting Micro and Small Enterprises access to finance. In addition to this, there fore mentioned contradiction between Tsehaye (2013) and studies performed in other countries and various inconsistencies in the literature indicate that it is quite important to thoroughly investigate factors affecting Micro and Small Enterprises This study therefore aims to assess factors affecting Micro and Small Enterprises access to finance in Gesuba Town and to recommend suitable measures to be taken.

\subsection{Statement of the Problem}

Despite the role of SMEs in the Ethiopian economy, they have not performed creditable well and hence has not played expected vital and vibrant role in the growth and development of the country. The financial constraints they face in their operations are daunting and this has had a negative impact on their development and also limited their potential to drive the national economy as expected. This is worrying for a developing economy without the requisite infrastructure and technology to attract big businesses in large numbers. In Ethiopian context, as to the Ethiopian government's strategy, Growth and Transformation plan, micro and small enterprises are the bridge to achieve the goals of the government (MoFED, 2011). But most SMEs in the country lack the capacity in terms of qualified personnel to manage their activities. As a result, they are unable to publish the same quality of financial information as those big firms and as such are not able to provide audited financial statement, which is one of the critical requirements in accessing credit from the financial institution.

As a result, information on their financial condition, earnings, and earnings prospect may be deficient or inaccurate. Faced with this type of doubt, a lender may deny credit, sometimes to the firms that are credit worthy but unable to report their results (Admasu, 2011). Another issue has to do with the inadequate capital base of 
most SMEs in the country to meet the collateral requirement by the financial institutions before credit is given out. In the situation where some SMEs are able to afford collateral, they often end up being inadequate for the amount they needed. These are some of the factors already acknowledged by some researchers as blocking most SMEs in accessing credit from the financial institution in the country. According to the information stated on SNNPR state Trade and Industry Bureau statistical abstract report (2009), Gesuba city have high number of MSEs when compared to sister towns Selamber and Humbo tebela, despite their performance. The report shows that 60 percent of business is failed with the first few months of operation and those that continue 80 percent fail before the fifth year.

MSEs have unique issues, which affect their growth and profitability and hence, diminish their ability to contribute effectively for sustainable development of the economy. Among those issues is access to in adequate credit which is universally indicated as a key problem facing MSEs. Wattanapruttipaisan (2003) stated that acute financial limitation becomes a strong barrier for MSEs in developing countries. Malhotra et al (2006) goes some way to confirm the above explanation that lack of access to finance is hindering the growth and competence of MSEs. In contrast to this, Riba (1999) argued that the key constraint for MSE growth, expansion, diversification and promotion is not the shortage of access to finance. It is rather lack of access to medium and long-term credit (time duration of credit) that hampers MSEs. There are also some authors who shared the arguments of both sides. Malhotra et al (2006) is a good case in point. In their article, they stated that the major constraints of MSEs which are not only lack of access to finance but also lack of medium or long term credit, suitable loan size, technology and know-how. Pissarides (2000) corroborates that credit constraints constitute one of the main obstacles to growth, expansion, diversification and promotion of MSEs.

The empirical studies of Gebrehiwot and Wolday (2006), who conducted their research on this subject in Ethiopia, pointed out that insufficient loan size, loan durations that do not match with the gestation periods and cash flow patterns of borrowers' activities financed by the loan, failure to disburse loans timely, and the tendency of group collateral requirements are the problems of MSEs in expanding and diversifying their enterprise. Studies carried out so far concluded that the problem of MSEs are access to working capital, inadequate infrastructure, high transactional cost, limited managerial and technical experts and marketing problems World Bank, (2008), Hailay (2003) and Gebrehiwot and Wolday (2006). Even though many authors have concluded the above mentioned problems of MSEs, they are still doing do not agree on each point. For example, Wattanapruttipaisan (2003) stated that lack of access to finance is a strong obstacle for MSEs in developing countries. In contrast, Riba (1999) argued that the major constraint for MSEs' growth, expansion, diversification and promotion is not the lack of access to finance rather its loan term, to medium and long-term credit, whereas Malhotra et al (2006) shared the arguments of both sides. The above mentioned contradiction between studies performed in other countries and various inconsistencies in the literature indicate that it is quite important to thoroughly investigate factors affecting Micro and Small Enterprises access to finance in Gesuba. Moreover, as per knowledge or information of researcher is concerned, there was no study conducted so far in Gesuba town on this issue, though there was an attempt made on regional and national levels. In line with the problem, research questions are raised here under:

- What is the nature of MSEs in accessing financial credit in Gesuba?

- What factors affecting MSEs in accessing credit facilities in Gesuba?

- What are the institutional factors that influence credit accessibility?

- What are the influences of possession of fixed asset on credit accessibility?

- What are the influence of education and maturation of operator on credit accessibility?

\subsection{Objectives of the Study}

\subsubsection{The General Objective of the Study}

The general objective of this study is to investigate the factors affecting micro and small enterprises in accessing credit facility in Gesuba.

\subsubsection{The Specific Objectives of the Study}

- To investigate the nature of MSEs in accessing financial credit across Gesuba.

- To identify major factors affecting MSEs in accessing financial credit in Gesuba.

- To identify the institutional factors that influence credit accessibility in Gesuba

- To investigate the influence of possession of fixed asset on credit accessibility

- To identify the influence of education and maturation of operator on credit accessibility

\subsection{Significance of the Study}

One of the major contributions of this study is to assist the Regional as well as Gesuba town Food security and Job creation department to establish mechanisms that are required to mitigate the constraints. The findings of this study are specifically concentrated on Factors affecting micro and small enterprises in accessing credit facility in Gesuba town. Therefore, the findings of the research was of great policy use and the outcome of the study will 
be useful to identify innovative options and institutional arrangements that would serve as an input for policy makers in formulating MSEs credit access policy. It can also assist banks and stakeholders of MSEs in identifying what are Factors affecting micro and small enterprises in accessing credit facility that actually existed in Ethiopian context. Further, the study is significant for the researcher's academic fulfillment in the requirements of graduation and important for an organization (MSEs) Unit of Analysis on which the problem was identified and research was made. It is a stepping stone for scientific community for further study, improvement and to in depth the investigation or testing the findings for replication to increase its reliability for theory building.

\subsection{Scope of the Study}

This paper was confined in investigating Factors affecting micro and small enterprises in accessing credit facility in Gesuba. In other words, MSEs operating outside Gesuba and business which do not fall under the improved definition of MSEs are not incorporated.

\subsection{Limitations of the study}

The limitations of the study were:

- $\quad$ The Zonal as well as Gesuba city Trade and industry department established newly as Food security and job creation department who oversees Small \& Micro Enterprises does not have adequate information regarding MSEs.

- Inadequacy of previous investigation in the area of study.

- Shortage of time for the study

\subsection{Organization of the study}

This thesis constitutes five chapters. In the first, introductory chapter including subtopics that are discussed include: background, statement of the problem, objectives of the study, significance of the study, scope and limitations of the study. The second chapter elaborates a review of some theoretical and practical concepts related to Credit access. Brief description of the study area and a thorough explanation of the methodologies used for the study are presented in chapter three. The findings of the study are presented in the results and discussions part in chapter four. Finally, chapter five deals with the conclusions and recommendation that are drawn from the study.

\section{METHODOLOGY OF THE STUDY}

\subsection{Research Design}

The research designs adopted in this research were both descriptive and explanatory in nature. The descriptive design was used to calculate basic statistics. These statistics would help to understand the general information of the respondent's answers. According to Churchill (1991), a descriptive research approach is used when the purpose is to describe the characteristics of a certain group, estimate the proportion of people specified in a certain way and to make specific predictions. The study was explanatory in that the relationship between variables is correlated with an aim of explaining the integrated influence of explanatory variables on access to finance (Koul, 2006; Irwin and Scott, 2010).

\subsection{Sampling Design}

As per the information availed from the Gesuba Trade and Industry Transport office, there are about 668 MSEs operates in Gesuba which are registered and renewed license for 2012 E.C. The following tables depict the distribution of MSEs by sector.

\section{Table 1: Number of MSEs in Gesuba by sector}

Sector

$\begin{array}{ll}1 & \text { Manufacturing } \\ 2 & \text { Construction } \\ 3 & \text { Services } \\ 4 & \text { Agriculture } \\ 5 & \text { Trade }\end{array}$

Total

Number of MSEs
100
158
201
65
144
$\mathbf{6 6 8}$

Source: Gesuba Trade and Industry Transport office (2019)

As exhibited in the above tables, the target population for the study is comprised of 668 Small and Micro Enterprises (MSEs). Hence, the sampling frame for this study has been chosen to be 668 SME operators in Gesuba city. Hence, MSEs at Gesuba town was constitute the population for the study. As described by Mugenda and Mugenda (2003) a simplified formula for calculating sample size of population that is less than 
10,000 is given

$\mathrm{nf}=\mathrm{n} /(1+\mathrm{n} / \mathrm{N})$

$\mathrm{nf}=$ the desired sample size when the population is less than 10,000

$\mathrm{n}=$ the desired sample when the population is more than 10,000

$\mathrm{N}=$ the estimate of the population size

$\mathrm{Nf}=384 /(1+384 / 668)=244$

Table 2: Sample size

Sector of MSEs

Manufacturing

Construction

Services

Agriculture

Trade

Total

$\begin{array}{|ll|}\text { Population } & \text { Sample size } \mathbf{3 6 . 5 \%} \\ 100 & 37 \\ 158 & 58 \\ 201 & 73 \\ 65 & 24 \\ 144 & 52 \\ \mathbf{6 6 8} & \mathbf{2 4 4}\end{array}$

Source: Gesuba Trade and Industry Transport office (2019)

The study used stratified random sampling method to select the sample. The study grouped the population in to strata. At the end by using proportionate stratified random sampling study selected 244 respondents.

\subsection{Data Type and Source}

This study was mainly quantitative in nature; it was strengthened by some aspect of qualitative data. The data were collected from primary sources. In order to assess the factors affecting micro and small enterprises in accessing credit facility, primary data were obtained by semi structured questionnaire and direct interview with the respondents. The respondents were micro and small enterprises in the study area and key informants from Gesuba Town Food security and Job opportunity creation department who oversees entire aspect of those enterprises. A cross-sectional research format was also employed in this study. Invariably this study employed cross-sectional data collected from micro and small enterprises in the study area and key informants from Gesuba Food security and Job opportunity creation department. The main reason for choosing for a cross sectional format was the study's interest to collect within one just time period.

\subsubsection{Data Collection Tools}

Conducting appropriate data gathering instruments help researchers to combine the strengths and amend some of the inadequacies of any source of data to minimize risk of irrelevant conclusion. Consistent and reliable research indicates that research conducted by using appropriate data collection instruments increase the credibility and value of research findings (Koul, 2006). Accordingly, to collect primary data, a semi structured questionnaire and check list were prepared. The questionnaires were pre-tested and amended based on the feedback to be reviewed.

\subsubsection{Method of Data Collection}

To assess the factors affecting credit access, primary data were collected through survey of MSEs (which comprises of access to credit and no access to credit) through the use of semi-structured questionnaire. The semistructured questionnaires were distributed to the operators of the micro and small enterprises (MSEs) which were designed to be filled primarily by their leaders. In an attempt to acquire quality data, collection of data by the use of semi-structured questionnaire was supplemented by conducting interview with some of the professionals and key government officials.

\subsection{Methods of Data Analysis}

For this research descriptive statistics was used to summarize the data collected from the sample respondents such as Frequency, cross tabulation, mean, standard deviation, and percentages. Also inferential statistics like Ttest and Chi-square test were used for comparing those who have access to credit and who haven't in various explanatory variables. In addition, an econometric regression model was applied for analyzing the data.

\subsubsection{Empirical Models}

Regression models in which the regress and evokes a yes or no or present or absent response are known as dichotomous, or dummy, dependent variable regression models. They are applicable in a wide variety of fields and are used extensively in survey or census-type data (Gujarati, 1995). The dependent variable in this study is also a dummy variable, which takes a value of zero or one depending on whether or not MSEs have access to credit. However, the independent variables are of both types that are continuous or categorical. When one or more of the explanatory variables in a regression model are binary, we can represent them as dummy variables and proceed to analysis. However, the application of the linear regression model when the dependent variable is binary is more complex and/or even not efficient (Pindyck and Rubinfeld, 1981). Binary choice models assume that individuals are faced with a choice between two alternatives and their choice depends on their behavior. Thus, one purpose of a qualitative choice model is to determine the probability that an individual with a given set 
of attributes will make one choice.

Access to credit is a dependent variable, which is dichotomous taking on two values, one if the MSEs have access and zero otherwise. Estimation of this type of relationship requires the use of qualitative response models. In this regard, the non-linear probability models, viz., logit and probit models are the possible alternatives. However, several estimation problems arise particularly when Ordinary Least Squares (OLS) regression and linear probability models are employed (Aldrich and Nelson, 1984). The OLS regression technique, when the dependent variable is binary, produces parameter estimates that are inefficient and a heteroscedastic error results in the structure. Consequently, hypothesis testing and construction of confidence interval become inaccurate and misleading. Likewise, a linear probability model may generate predicted values outside the $0-1$ interval, which violates one of the basic tenets of probability. To alleviate these problems and produce relevant empirical outcomes, the most widely used qualitative response models are the logit and probit models (Amemiya, 1981). Probit and logit models are similar and yield essentially identical results. Aldrich and Nelson (1984) indicated that in practice these models yield estimated choice probabilities that differ by less than 0.02 and which can be distinguished, in the sense of statistical significance, only with very large samples. The choice between them therefore, revolves around practical concerns such as the availability and flexibility of computer programs, personal preference, experience and other facilities.

The logit models are commonly used in studies involving qualitative choices. The probit probability model is associated with the cumulative normal probability function, whereas, the logit model assumes cumulative logistic probability distribution. The advantage of these models over the Linear Probability Model is that the probabilities are bound between 0 and 1. Moreover, they fit best the non-linear relationship between the probabilities of the dependent variable and the explanatory variables; that is one which approaches zero at slower and slower rates as an explanatory variable $\left(X_{t}\right)$ gets smaller and smaller and approaches oneat slower and

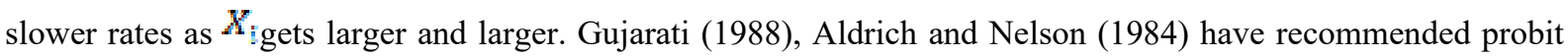
model for functional forms with limited dependent variables that are continuous between 0 and 1 , and logit models for discrete dependent variables. An extension of the probit model is the Tobit model. In Tobit, which is an example of a general class of models known as censored regression models (also known as limited dependent variable models), values of the regress and are not available for some observations, although values of the repressors are available for all the observations? Such models are usually estimated by the maximum likelihood methods (Gujarati, 1995). Comparing with discriminant analysis model, (the probit and logit models appear to be preferable to discriminant analysis for analyzing studies involving qualitative choices (Feder, Just, and Zilberman, 1985).

\subsubsection{Specification of the Logit Model}

This study is intended to analyze which and how much the hypothesized repressors were related to the credit access of micro and small enterprises. As already noted, the dependent variable was a dummy variable, which took a value zero or one depending on whether or not an enterprise accessed credit. However, the independent variables were of both types, that is, continuous or categorical. In the analysis of studies involving qualitative choices, usually a choice has to be made between logit and probit models. According to Amemiya (1981), the statistical similarities between logit and probit models make the choice between them difficult. However, Maddala (1983) and Kmenta (1986) reported that many authors tend to agree in that the logistic and cumulative normal functions are very close in the mid-range, but the logistic function has slightly heavier tails than the cumulative normal functions. Gujarati (1988) illustrated that the logistic and probit formulations are quite comparable, the main difference being that the former has slightly fatter tails; that is, the normal curve approaches the axes more quickly than the logistic curve. Hosmer and Lemeshew (1989) pointed out that a logistic distribution (logit) has got advantage over the others in the analysis of dichotomous outcome variable in that it is extremely flexible and easily used model from mathematical point of view and results in a meaningful interpretation. Hence, the logistic model is selected for this study.

Assume that there exists a latent (unobserved) variable such that:

$y_{t}{ }^{n}=\beta x_{i}+u_{t}$

$y^{*}=1$ if $y_{t}^{*}>0 ; \quad$ otf $y_{t}^{*} \leq 0 \quad$ Where:

$y_{t}^{*}=$ a vector of latent variable that is not observed for values less than zero and greater than one,

$y^{*}=$ the observed variable, representing the proportion of credit access,

$\beta=$ the unknown parameters that reflecting the impact of change in variable $\mathrm{X}$,

$X_{i}=$ explanatory variables that determine the dependent variable,

$u_{i}=$ error terms that is distributed normally with mean 0 and variance $\sigma 2$,

$i=1,2,3 \ldots . \mathrm{n}$, represents the number of observations. 
$\operatorname{prob}(Y=1)=\frac{1}{1+e^{-z_{1}}}$

Taking the natural logarithm is:

$$
z_{i}=\operatorname{In}\left(\frac{p_{1}}{1-p_{1}}\right)=\propto+\beta_{1} X_{1}+\beta_{z} X_{2}+\ldots \beta_{m} X_{m}
$$

If the error term $\left(u_{i}\right)$ is taken in to account, the Logit model becomes:

$z_{i}=\propto+\sum_{i=1}^{m} \beta_{i} x_{i}+u_{i}$

The dichotomous response variable $Z_{i}\left(Y_{i}\right)=0$ or 1 with $Y=1$ denotes the occurrence of the event of interest while $\mathrm{Y}=0$ denotes otherwise. The dummy variables, also identified as indicators and bound variables, characterize dichotomous responses. In this study, since only two options are available, namely "access to credit" or "no access to credit" a binary model was set up to define $Y=1$ for situation where MSEs accessed credit and $\mathrm{Y}=0$ for situations where MSEs did not access credit from formal sources. The logistic regression in this study can therefore be specified as: $\mathrm{Yi}=\alpha+\beta 1 \mathrm{X} 1+\beta 2 \mathrm{X} 2+\ldots \ldots \beta \mathrm{nXn}+\mathrm{Ui}$

Where: $X_{1} \ldots n$ are explanatory variables; $\beta 1 \ldots n$ are the slope coefficients; $u_{1}$ is error term The finally employed model has the following form:

CREDacc $=\alpha+\beta 1$ OPRage $+\beta 2$ OPRgen $+\beta 3$ OPReduc $+\beta 4$ ENTass $+\beta 5$ ENTage $+\beta 6$ ENTsize $+\beta 7$ ENTsector $+\beta 8 \mathrm{INT}+\beta$ LLEND $+\beta 10 \mathrm{LEP}+\mathrm{Ui} \quad$ Where

CREDacc $=$ Access to formal credit

OPRage $=$ Age of operator

OPRgen $=$ Gender of operator

OPReduc $=$ Educational level of the operator

ENTass $=$ Possession of fixed assets

ENTage $=$ Age of the enterprise

ENTsize $=$ Firm size

ENTsector $=$ Business sector

INT $=$ Interest rate

LEND $=$ Lending procedures

LEP=Inflexible loan repayment period

$\alpha=$ Constant (intercept)

$\beta 1-\beta 10=$ Coefficients

$\mathrm{Ui}=$ Error term

\subsubsection{Sensitivity Analysis}

The parameters of the model are estimated using the iterative maximum likelihood estimation procedure. In reality, the significant explanatory variables do not all have the same level of impact on credit access of micro and small enterprises. The relative importance of quantitative explanatory variables affecting credit access can be measured by examining variable elasticity, defined as the percentage change in probabilities that would result from a percentage change in the value of these variables. To compute the elasticity, one needs to select a variable of interest, calculate the associated $P_{i}$, vary the $X_{i}$ of interest by some small amount and re-compute the $P_{i}$, and then measure the rate of change as $d P_{t} / d X_{t}$, where $d X_{t}$ and $d P_{t}$ stand for percentage changes in the continuous explanatory variable $\left(X_{i}\right)$ and in the associated probability levels $\left(P_{i}\right)$, respectively. When $d X_{i}$ is very small, this rate of change is simply the derivative of $P_{i}$ with respect to $X_{i}$ and is expressed as follows (Aldrich and Nelson, 1984):

$$
\frac{d P_{t}}{d X_{t}}=\frac{e^{z_{t}}}{\left(1+e^{2} \gamma^{2} \beta_{t}\right.}=P_{t}\left(1-P_{t}\right) \beta_{t}
$$

The impact of each significant qualitative explanatory variable on the probability of no access to credit of a typical MSE, who represents the characteristics of the majority of the MSE, is calculated by keeping the continuous variables at their mean values and the dummy variables at their most frequent values (zero or one).

\subsubsection{Parameter Estimation}

To fit the logistic regression model, the estimation of the values of the unknown parameters $\alpha_{\text {and }} f_{t}{ }_{t} s$ are required. In linear regression, the Least Square Estimation (OLS) method is used to estimate the parameters of 


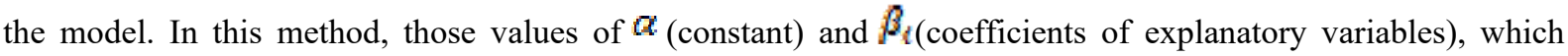
minimize the sum of squared deviations of the observed values of $Z_{i}$ (dependent variable) from the predicted values are determined. Under the assumptions of linear regression, the method of least squares yields estimators with a number of desirable statistical properties. Unfortunately, when the method of OLS is applied to a model with a dichotomous outcome the estimators no longer have these same properties (Hosmer and Lemshow, 1989; Gujarati, 1988).

Since the method of OLS does not make any assumptions about the probabilistic nature of the disturbance term $\left(\boldsymbol{u}_{\mathfrak{t}}\right)$, in logistic regression, the parameters of the model are estimated using the maximum likelihood (ML) method (Maddala, 1989; Gujarati, 1988). Due to the nonlinearity of the logistic regression model, an iterative algorithm is necessary for parameter estimation. Maddala (1989) pointed out that the method of ML is a very general method of estimation that is applicable to a large variety of problems. The ML method of estimation suggests choosing estimates as the values of the parameters that maximize the likelihood function (Maddala, 1989). In many cases it is convenient to maximize the logarithm of the likelihood function rather than likelihood function itself and the same results are obtained (Maddala, 1989). Hosmer and Lemeshow (1989) concluded that in a very general sense, the method of ML yields values for the unknown parameters, which maximize the probability of obtaining the observed set of data. Mostly this method is preferred when large sample size is used.

Before taking the selected variables into the logit model, it is necessary to check for the existence of multicollinearity among the continuous variables and verify the degree of association among discrete variables. The reason for this is that the existence of multicollinearity will affect seriously the parameter estimates. If multicollinearity turns out to be significant, the simultaneous presence of the two variables will attenuate or reinforce the individual effects of these variables. However, omitting significant interaction terms incorrectly will lead to a specification bias. To put it in a nut shell, the coefficients of the interaction of the variables indicate whether or not one of the two associated variables should be eliminated from model analysis (Kothari, 1990).

Accordingly, a Variance Inflation Factors (VIF $\left(X_{i}\right)$ ) technique was employed to detect the problem of multicollinearity for continuous variables (Gujarati, 1995). Each selected continuous explanatory variable $\left(X_{i}\right)$ is regressed on all the other continuous explanatory variables, the coefficients of determination $\left(R_{i}^{2}\right)$ being constructed in each case. If an approximate linear relationship exists among the explanatory variables then this should show up as a 'large' value for $\boldsymbol{E}_{i}{ }^{2}$ in at least one of the test regressions. A popular measure of multicollinearity associated with the $\operatorname{VIF}\left(X_{i}\right)$ is defined as:

$$
\operatorname{VEF}\left(X_{i}\right)=\left(1-R_{i}^{2}\right)-1 \quad \text { Where, }
$$

$R_{j}^{2}$ - is the coefficient of multiple determinations when the variable $X_{j}$ is regressed on the other explanatory variable. A rise in the value of $R_{F}^{2}$ that is an increase in the degree of multicollinearity does indeed lead to an increase in the variances and the standard errors of the OLS estimators. A VIF value greater than 10 is used as a signal for the strong multicollinearity (Gujarati, 1995). Similarly, there may also be interaction between two qualitative variables, which can lead to the problem of high degree of association between two variables. To detect this problem, contingency coefficients were computed from the survey data. The contingency coefficients are computed as follows:

$C=\sqrt{\frac{x^{2}}{x+x^{2}}} \quad$ Where,

$C=$ coefficient of contingency,

$\chi 2=$ Chi-square random variable and

$N=$ total sample size.

\subsubsection{Testing Hypotheses about the Coefficients}

Separate tests of the null hypothesis that individual coefficients are zero can be computed using t-test of the multiple linear regression models (Gujarati, 1988). This test can be used to see the statistical significance of each coefficient. An overall test of the null hypothesis that all the parameters associated with the explanatory variables in these models are equal to zero is an F-test based on the OLS estimation procedure. In logit and other probability models, the most commonly used test is the likelihood ratio statistic, which approximately follows the Chi-square $(\chi Z)$ distribution (Liao, 1994). In the ML estimation method, a log likelihood ratio test replaces the usual F-test of OLS regression models to evaluate the significance of all or a sub-set of coefficients (Aldrich 
and Nelson, 1984; Pindyck and Rubinfeld, 1981). The Chi-square tests the null hypothesis that the coefficients for all terms in the current model except the constant are zero. The log likelihood ratio statistic follows a Chisquare distribution with $\mathrm{k}$ degrees of freedom (where $\mathrm{k}$ is the number of parameters in the equations less the constant) and is calculated as the difference between -2 times log likelihood for the model with only a constant and -2 times log likelihood for the current model:

$x^{2}--2(\ln E Q-\ln L \max )$ Where,

$L O$ is the value of the likelihood function for the constant only and $E_{m} m x$ is the value of the likelihood function when all or a sub-set of independent variables are included in the model (Maddala, 1989; Kementa, 1986; Pindyck and Rubinfeld, 1981).

\subsubsection{Interpretation of Parameter Estimates}

In multiple linear regressions, the interpretation of the coefficient is straightforward. It tells the amount of change in the dependent variable for a unit change in the independent variable. The interpretation of logistic regression coefficients $\left(\beta_{t}\right)$ is considered by using odds ratio $\left[\frac{\boldsymbol{s}_{i}}{1-p_{1}}\right]$ and $\log$ of the odds ratio $\left[\ln \left(\frac{\boldsymbol{B}_{i}}{1-p_{i}}\right)\right]$ (Liao, 1994). The odds value gives the expected change in the odds ratio of access to credit versus no access to credit per unit change in an explanatory variable, other things being equal. The same interpretation applies to both dummy and continuous variables (Liao, 1994). The logistic regression slope coefficient can be interpreted as the change in the log odds associated with a unit change in the independent variable $\left(X_{i}\right)$, i.e., it tells how the $\log$ odds in favor of defaulting changes as $X_{i}$ changes by one unit. The $\alpha$ is the log odds in favor of being no access to credit if $X_{i}$ is zero.

\subsection{Working Hypotheses and Definitions of Variables}

Among a number of factors, which have been related to MSEs' Access to credit facilities, in this study, the following factors are hypothesized to explain factors affecting micro and small enterprises in accessing credit facility from formal financial institutions in the study area.

Dependent variable (CREDacc): Is defined as the access to credit facility for MSEs, which is a dummy variable taking a value one if the MSEs have access to credit and zero otherwise.

Independent Variables

Age of operator (OPRage): It is defined as the number of years the respondent operator since birth until the survey was conducted. It is a continuous variable measured by years. Through time operator acquire experience in the business and/or have the potential to influence access to credit. Therefore, this variable is hypothesized to have positive impact on access to credit facilities.

Gender of operator (OPRgen): is defined as the sex of male- and female-operated firms. A survey made on small business found tough univariate evidence of differences in the availability of credit to male-operated and female-operated firms. More specifically, female-operated firms are significantly more likely to be creditconstrained because they are more likely to be discouraged from applying for credit (Rebel and Hamid, 2009). This variable takes a value one if the operator is male and zero otherwise.

Educational level of the operator (OPReduc): Educational back ground of the SME owner-manager is often positively related to the firm's usage of leverage (Coleman, 2007). Entrepreneurs with higher education, more work experience and skills are likely to have superior abilities, achieve higher performance, develop good reputations and become more successful in accessing external finance than novice entrepreneurs with a lower or less human capital (Charles, 2009). Therefore, this variable is hypothesized to have positive impact on access to credit facilities.

Possession of Fixed Asset (ENTass): Anthony et al. (2013) found a positive relationship between collateral security and the amount of loan realized. Odit and Gobardhun (2011) concluded that access to debt finance is affected by the positive association between the debt ratio and the asset structure. Furthermore, they revealed that SMEs with a lower portion of tangible assets in their total assets are more likely to encounter difficulties in applying for outside finance because of the inability to provide the collateral required. Therefore, this variable is hypothesized to have positive impact on access to credit facilities

Age of the enterprise (ENTage): is defined as the total time the enterprise was stayed at operation until the date of survey. Abor and Biekpe (2009) suggest that a firm which has operated for long has reputation that it has built up over the years, which is understood by financial markets. Startup firms are likely to face financing problems and a firm's access to finance depends on its stage of development. In addition, Fatoki and Asah (2011) observed that SMEs established more than five years have a far better chance to be successful in their credit applications compared with SMEs established for less than five years. Therefore, this variable is hypothesized to have positive impact on access to credit facilities

Firm Size (ENTsize): Gebru (2009) found that compared to large firms, MSEs face a relative disadvantage to 
raise finance from formal institutions such as banks because they are considered to have higher financial risk. Cassar (2004) argues that it may be relatively more costly for smaller firms to resolve information asymmetries with debt providers. Consequently, smaller firms may be offered less debt capital. Therefore, this variable is hypothesized to have positive/negative impact on access to credit facilities

Business Sector (ENTsector): In a study performed on Micro and small Enterprises in Zimbabwe, business sector in which the enterprise is operating was found to be a very important factor in accessing loans. Martin and Daniel (2013) also found that the industry with which the business belongs was also found to have an implication on access to finance. In terms of the trade-off hypothesis, businesses with mostly tangible assets (like construction and manufacturing) should borrow more because of the collateral provided by their assets (Jordan et al., 1998).

Interest rate (INT): Anthony et al (2013) who studied determinants of credit rationing to the private sector in Ghana found out that interest rate has a negative effect on credit allocation. Higher interest rate discourages micro and small enterprises to deepen their financial access.(Sacerdot, 2005). Stiglitz and Weiss (1981) further show that higher interest rates induce firms to undertake projects with lower probability of success but higher payoffs when they succeed (leading to the problem of moral hazard). Therefore, this variable is hypothesized to have negative impact on access to credit facilities

Lending procedures (LEND): Green (2003) argued that limited access of small enterprises to formal credit in developing and emerging economies is largely due to the relatively underdeveloped nature of the financial system, the lack of liquidity, and inexperience in small-scale lending in many of these countries. Financial institutions outside the capital cities frequently provide only cash and do not have the authority to make loans, leaving small enterprises disproportionally disadvantaged. If financial institutions do extend credit to small firms, it may take up to several months to process applications. Therefore, this variable is hypothesized to have negative impact on access to credit facilities

Inflexible Loan repayment period (LEP): In a study conducted by Richard (2010) on Ugandan SMEs, it was found out that the maximum loan amounts were not adequate enough for the borrowers to meet their due financial needs and financial institutions are strict with their collection procedures. Repayment period does influence financial decisions of the MSEs borrowers and if the credit period does not match the current cash flows, then some important strategies have to be put in place such as delaying the dividend payment, since there is need to pay up the loan.

\section{Table 3 Summary of explanatory variables and their expected effect}

$\begin{array}{llll}\text { No. } & \text { Independent variables } & \text { Variable Type } & \text { Expected effect } \\ 1 & \text { Age of operator (OPRage) } & \text { Continuous } & \text { Positive } \\ 2 & \text { Gender of operator (OPRgen) } & \text { Dummy } & \text { Negative } \\ 3 & \text { Educational level of the operator (OPReduc) } & \text { Dummy } & \text { Positive } \\ 4 & \text { Possession of fixed assets (ENTass) } & \text { Continuous } & \text { Positive } \\ 5 & \text { Age of the enterprise (ENTage) } & \text { Continuous } & \text { Positive } \\ 6 & \text { Firm size (ENTsize) } & \text { Continuous } & \text { positive } \\ 7 & \text { Business sector (ENTsectr) } & \text { Dummy } & \text { Positive } \\ 8 & \text { Interest rate (INT) } & \text { Dummy } & \text { Negative } \\ 9 & \text { Lending procedures (LEND) } & \text { Dummy } & \text { Negative } \\ 10 & \text { Loan repayment period (LEP) } & \text { Dummy } & \text { Positive }\end{array}$

\section{RESULTS AND DISCUSSION}

\subsection{Introduction}

This chapter presents the results from descriptive and econometric analyses of factors affecting micro and small enterprises in accessing credit facility in the study area. The descriptive analysis made use of tools such as mean, percentages and standard deviation. In addition, the t- and chi-square statistics were employed to compare those who have access to credit and no access to credit with respect to some explanatory variables. Econometric analysis was carried out to identify the most important factors that affect micro and small enterprises in accessing credit facility and to measure the relative importance of significant explanatory variables on credit access.

\subsection{Descriptive Analysis}

The demographic characteristics of the respondents such as age, sex, marital status, religion, educational background, enterprise size, enterprise sector and other variables related to MSEs (credit access or no credit access) were analyzed by using descriptive statistics.

\subsubsection{Credit Access Status of the Sample Respondents}

To conduct this study, the researcher has initially aimed at collecting data from 244 operators of MSEs. However, the non-response and non-filling rate together accounted for 17 percent; and hence the actual data gathered for 
the present study is from a total of 202 sample operators of MSEs. To determine the credit access status of MSEs, the qualitative data was collected from the respondents. Those who got access to credit from formal source were categorized as positive outcome and vice versa. The survey result shows that from 202 sample respondents, 111(55 percent) MSEs didn't get credit access and 91(45 percent) were found to be MSEs with credit access.

Table 4 : Distribution of sample respondents by credit access status

\begin{tabular}{|lccc|}
\hline Credit Access status & Frequency & Percent & Cumulative \\
\hline Access to credit & 91 & 45 & 45 \\
\hline No access to credit & 111 & 55 & 100 \\
\hline Total & 202 & 100 & \\
\hline
\end{tabular}

Source: Survey data, March 2019/20

3.2.2 Socio-demographic Characteristics of Sample Respondents

Many scholars believe that the socio-demographic characteristics of the respondents have an important implication for access to credit. In this section, rough analyses have been made to examine the relationship between socio-demographic characteristics and the credit access status of the respondents. Some of an important socio-demographic characteristics such as age, sex, marital status, religion, and literacy status of the respondents are selected and their corresponding relationship with the respondents credit access status have been demonstrated.

Table 5 Gender of the respondents by credit access status

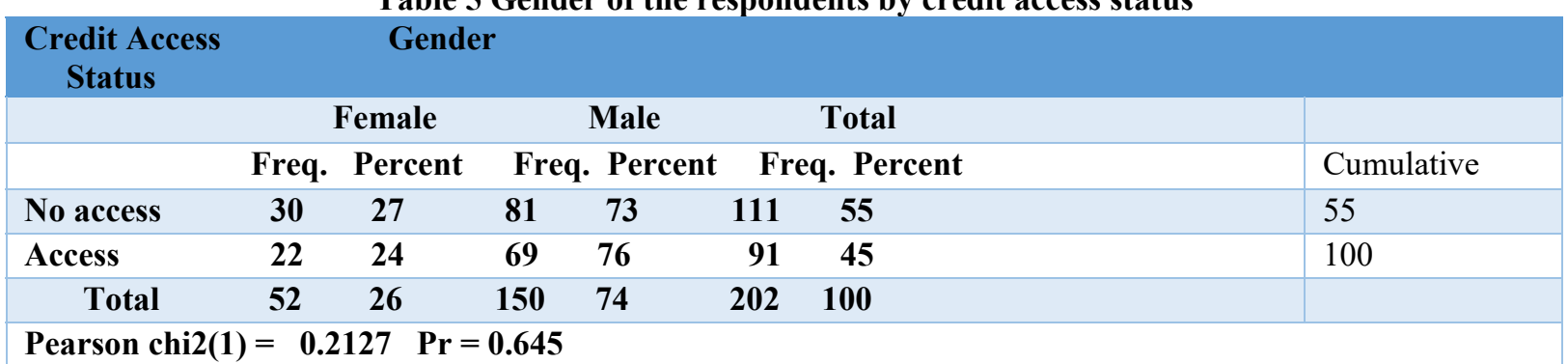

Source: Survey data, March 2019/20s

As depicted in table 5 above, MSEs with the female and male leaders in the overall sample respondents are 26 and 74 percent, respectively. From the total of 45 percent of MSEs with credit access, about 24 percent constitutes enterprises led by females and the rest 76 percent are led by males. Similarly, out of 55 percent of MSEs who didn't get credit access, 27 percent are led by females and 73 percent are led by male. This shows that there is a great disparity within each of credit access groups in such that leaders of MSEs are essentially males. Nonetheless, the result of chi-square test has revealed that there is statistically insignificant difference in accessing credit facility between MSEs led by male and female. This implies that the odds of getting credit doesn't affected by being led by either of the two sex groups.

Table 6: Ages of the Respondents by credit access category

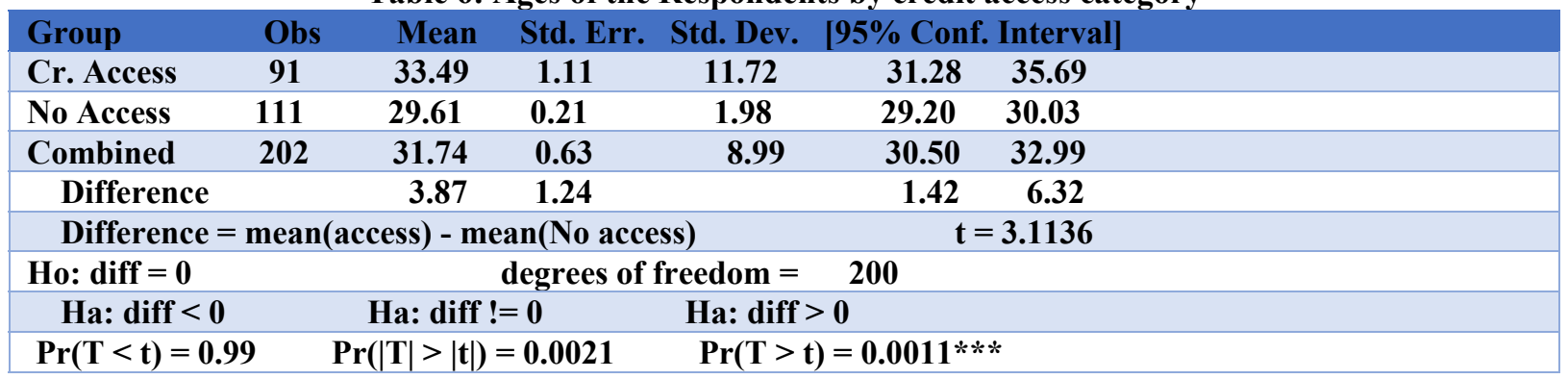

Note: $\quad * * *$ significant at $1 \%$ level of significance

Source: Survey data, March 2019/20

There exists a strong argument among scholars with regard to the relationship between age of the MSE leader and the enterprise's respective credit access status. The is that as the age of the enterprise leader increases, he/she is likely to acquire more experience on the business practice and forecast the likely return on borrowing. The survey result as depicted in the table 6 above shows that, on average, age of the MSE leader is positively related with the enterprise's credit access status and this is consistent with arguments by many scholars. As table 3 above presents, the mean age of the MSE leaders in the overall sample is nearly 32 with standard deviation of 8.99. The mean age of enterprise leaders who didn't get access to credit is just about 30 years and that of the enterprise leaders who have access to credit is around 34 years, having the resultant standard deviation of 1.98 and 11.72, respectively. The mean age difference between these two groups is statistically significant at $1 \%$ level of significance having the $t$ statistic of 3.1136 and $\operatorname{Pr}(T>t)=0.0011$. This means that as the age of the enterprise 
leader increases, the odds of the enterprise to have credit access increases; and this result has confirmed the prior expectation of the researcher.

Table 7: Marital Status of Respondents by credit Access status

\begin{tabular}{|l|l|l|l|l|l|l|l|l|}
\hline \multicolumn{8}{|c|}{ Credit Access Status } \\
\hline & No access & With access & Total & Cumulative \\
Marital Status & Freq. & Percent & Freq. & Percent & Freq. & Percent & Percent \\
\hline Single & 68 & 61.26 & 47 & 51.65 & 115 & 56.93 & 56.93 \\
\hline Married & 38 & 34.23 & 41 & 45.05 & 79 & 39.11 & 96.04 \\
\hline Divorced & 3 & 2.70 & 2 & 2.20 & 5 & 2.47 & 98.51 \\
\hline & Widowed & 2 & 1.80 & 1 & 1.09 & 3 & 1.49 & 100.00 \\
\hline
\end{tabular}

Source: Survey data, March 2019/20

Table 7 above presents the relation between marital status and MSEs credit access status. The survey result shows that 39.11 percent of the respondents are married. Divorced and widowed respondents occupy a little share of the sample enterprise leaders owing only to $2.47 \%$ and $1.49 \%$ percent, respectively. The marital status between enterprises who have access to credit and who don't have such an access is statistically insignificant. Hence, with chi2 $(3)=2.5266$ and $\operatorname{Pr}=0.471$, we cannot reject the null hypothesis at any acceptable level of significance. This means that marital status has nothing to do with the credit access status of the respondents.

Table 8: Start-up capital of the respondents by credit access status

\begin{tabular}{|cccc|}
\hline Source of start-up capital & $\begin{array}{c}\text { Credit Access } \\
\text { No access }\end{array}$ & with access & Total \\
\hline Personal Saving & 48 & 53 & 90 \\
\hline Friends/relatives & 63 & 27 & 101 \\
\hline Microfinance & 0 & 11 & \\
\hline Total & 111 & 91 \\
\hline Pearson $\operatorname{chi} 2(2)=23.9016$ & $\mathrm{Pr}=0.000$ & & \\
\hline
\end{tabular}

Note: ***significant at 1\% level of significance Source: Survey data, March 2019/20

The source of start-up capital for MSEs who have access to credit is dominated by personal savings followed by contributions from friends and/or relatives, and then loans from microfinance institutions. Similarly, enterprises with no credit access group gets source of initial capital from friends and/or relatives followed by personal saving. This is depicted in table 8 above. As the survey result clearly shows, there is a statistically significant difference between the two groups with respect to their source of initial capital. Hence, with Pearson chi2 $(2)=23.9016$ and $\operatorname{Pr}=0.000$ values, we can reject the null hypothesis which assumes similar source of start-up capital for both category of enterprises.

Table 9: Education level of the respondents by credit access status

\begin{tabular}{|lccc|}
\hline & \multicolumn{2}{c}{ Credit Access } & \\
\hline Education level & No access & with access & Total \\
\hline Illiterate & $\mathbf{4 5}$ & $\mathbf{1 2}$ & $\mathbf{9 0}$ \\
\hline Primary & $\mathbf{3 1}$ & $\mathbf{1 8}$ & $\mathbf{1 0 1}$ \\
\hline Secondary & $\mathbf{2 8}$ & $\mathbf{2 4}$ & $\mathbf{5 2}$ \\
\hline Diploma \&Above & $\mathbf{7}$ & $\mathbf{3 7}$ & $\mathbf{4 4}$ \\
\hline Total & $\mathbf{1 1 1}$ & $\mathbf{9 1}$ & $\mathbf{2 0 2}$ \\
\hline Pearson chi2 $(2)=19.7218 \quad \mathrm{Pr}=0.000$ & & & \\
\hline
\end{tabular}

Note: ***significant at 1\% level of significance Source: Survey data, March 2019/20

As clearly indicated in the table 9 above, the education level of sample respondents varies between leaders MSEs which have access to credit and no access to credit. The survey result indicated that as the education level of the leader increases, it is likely that they can easily deal with the institution providing the loan and can win in getting loan. The Pearson chi2(2) $=19.7218$ and $\operatorname{Pr}=0.000$ values confirmed that there is statistically significant difference between enterprise leaders' educational achievement and their respective ability to deal with loan provider. Thus, we can reject the null hypothesis which says there is no statistically substantial difference between the two groups regarding their leaders' level of education. 
Table 10: Business Sector under MSEs by Credit Access Status

\begin{tabular}{|lccc|}
\hline & \multicolumn{3}{c|}{ Credit Access } \\
\hline Business sector & No access & With access & Total \\
\hline Construction & 33 & 10 & 43 \\
\hline Agriculture & 29 & 13 & 42 \\
\hline Service & 23 & 21 & 44 \\
\hline Trade & 18 & 26 & 44 \\
\hline Manufacturing & 6 & 31 & 37 \\
\hline \multicolumn{1}{c|}{ Total } & 111 & 91 & 202 \\
\hline & Pearson chi2(4) $=\mathbf{8 . 1 4 8 5}$ & Pr $=\mathbf{0 . 0 8 6}$ \\
\hline
\end{tabular}

Note: * significant at 10\% level of significance Source: Survey data, March 2019/20

Analysis of the business sectors in which micro and small enterprises are engaged in relation to their respective access to credit has also an important implication. It gives an insight for new enterprises to invest in the sector where financial institutions supply loans with easy procedure. As is presented in Table 10 above, enterprises which are operating in the manufacturing and trade receiving loans are large in number compared to those who are operating in the construction, agricultural, and service sectors. This is due to the fact that manufacturing sector is a highly favored sector by the government and hence it is a policy priority. This is revealed by the Pearson chi2 $(4)=8.148$ and $\mathrm{Pr}=0.086$ values, suggesting that the difference in the number of enterprises operating across different business sectors between MSEs who gets loan and those who didn't get the loan is statistically significant at $10 \%$. However, we can reject the null hypothesis only at a higher level of significance. In interview with key informants, almost all of them responded that the major challenge for MSEs to access credit is lack of collateral flowed by negative attitude of loan repayment period and lending procedure. Most of the interviewee responded that aged and educated operators are influential in accessing credit facility.

\subsection{Econometric Results}

Before running the logistic regression model, both the continuous and discrete explanatory variables were checked for the existence of multi-collinearity problem. In this study, Variance Inflation Factor (VIF) was used to test the presence of multi-collinearity. In this study, there is no value greater than 10 (see appendix3) and therefore no multi-collinearity problem. In addition, correlation matrix was used to illustrate bivariate relationship between two independent and dependent variables. Since generally Multicollinearity is a problem when the correlation result is above 0.80 and below -0.80 , but in this study it is between 0.453 and -0.324 (see appendix3). In order to avoid hetroskedasticity problem, MSEs access to credit was estimated by using logistic model which solves the problem of heteroskedasticity (see appendix 3). The best model selected was based on the the Chi-Square tests. The value of Pearson Chi square test shows that the overall goodness of fit of the model fits the data at less than $1 \%$ level of significance (see appendix 3 ).

The binary logit model was used to identify the major factors affecting MSEs' access to formal sources of credit. In the logit model analysis, we emphasize on considering the combined effect of variables between MSEs' that are formal credit users and non-users in the study area. The importance therefore, is on the joint analysis of the variables. The result of the binary regression model shows the odds of having access to credit i.e. $\mathrm{P}(\mathrm{Y}=1)$. The variables that were found to be significant at 10 percent, $5 \%$, and $1 \%$ have been indicated with $(*)$, $(* *)$ and $(* * *)$, respectively. Below is a summary of the results of the logistic regression model.

Possession of Fixed Asset (ENTass): According to survey result, the variable possession of fixed asset has a positive and statistically significant effect on MSEs access to credit from formal financial institutions at $10 \%$ level of significance. With an odds ratio of 1.958, MSEs which have fixed asset are 1.958 times more likely to access credit from formal financial institutions than MSEs which do not. This result is consistent with previous studies by (Anthony et al., 2013; Mabhungu et al., 2011; Odit and Gobardhun 2011 and Wu et al., 2008) and is contrary to a study by (Tsehaye, 2013). Financial institutions are more likely to approve loans to firms that are able to provide collateral. Due to the existence of asymmetric information, formal financial institutions base their lending decisions on the amount of fixed asset available. Collateral acts as a screening/rationing device and reduces the risk of lending for financial institutions. By pledging his assets, a borrower signals the quality of his project and his intention to repay. In the case of 
Table 11: Logistic Regression Estimation Results

\begin{tabular}{|l|l|l|l|l|}
\hline Variables & Coefficient & Wald statistics & $\begin{array}{l}\text { Significance } \\
\text { level }\end{array}$ & Odds ratio \\
\hline operator's age(reference $>40)$ & & - & - & \\
\hline $18-25$ & -.86 & .866 & .366 & .429 \\
\hline $26-30$ & -.421 & .272 & .636 & .666 \\
\hline $31-35$ & -2.256 & 4.47 & $.034^{* *}$ & .105 \\
\hline $36-40$ & -1.006 & .969 & .325 & .366 \\
\hline Gender & .346 & .338 & .561 & 1.414 \\
\hline Educational Level(reference & & & & \\
\hline TVET/College and above) & & - & - & $.027^{* *}$ \\
\hline No formal education & -2.901 & 4.867 & .187 & .055 \\
\hline Primary school & -1.03 & 1.741 & .272 & .357 \\
\hline Secondary school & -.665 & 1.207 & $.094 *$ & 1.958 \\
\hline Possession of fixed asset & .672 & 2.81 & - & \\
\hline Employment Size(reference $>5)$ & & - & $.007 * * *$ & .14 \\
\hline Employment Size $(<5)$ & -1.968 & 7.219 & .154 & .321 \\
\hline Employment Size 5-31 & -1.138 & 2.031 & .319 & .431 \\
\hline Employment Size $>31$ & -.841 & .995 & - & \\
\hline Sector(reference Manufacturing) & & - & .41 & 1.968 \\
\hline Construction & .677 & .677 & .395 & 2.301 \\
\hline Urban agriculture & .833 & .725 & .64 & .677 \\
\hline Service & -.39 & .219 & .611 & .647 \\
\hline Trade & -.435 & .275 & .68 & .811 \\
\hline Interest rate & -.223 & .17 & $.013^{* *}$ & .234 \\
\hline Lending procedure & -1.454 & 6.128 & $.079 *$ & \\
\hline Loan repayment period & -.734 & 3.095 & & \\
\hline Source Survey & & & & \\
\hline
\end{tabular}

Source: Survey data, March 2019/20

Note: *,**, and *** indicates the level of significance $10 \%, 5 \%$, and $1 \%$ level of significance

Default, collateral serves to put the lender into a fortunate position with regard to other creditors. Small firms are disadvantaged in this regard, due to the fact that they lack collateral security and also they lack a proven credit track record. Therefore, start-up firms with new innovative products may be constrained access to finance due to the fact that they may fail to furnish collateral security and also due to information asymmetries, financial institutions may fail to see the profitability and viability of the proposals (Green, 2003).

Lending procedures (LEND): The variable lending procedure has a negative and statistically significant relationship with MSEs' access to credit from formal financial institutions at 5\% level of significance. With an odds ratio of 0.234 , MSE operators who have a negative attitude about lending procedure are 0.234 times less likely to access credit from formal financial institutions than those who do not. This result is consistent with a study by Green (2003). To get formal loans entrepreneurs are expected to pass through different processes, which is time-taking, cumbersome and sometimes difficult to understand. Rather they prefer to take loan from the informal credit institutions for the sake of ease even if it charges higher interest rates. Schmidt and Kropp (1987) pointed out that in most cases the access problem especially among formal financial institutions, is often created because lending policies. When terms of payment, required security and the provision of supplementary services do not fit the needs of the target group, potential borrowers will not apply for credit even where it exists and when they do, they will be deprived of access (Schmidt and Kropp, 1987).

Loan repayment period (LEP): The variable loan repayment period has a negative and statistically significant relationship with MSEs' access to credit from formal financial institutions at $10 \%$ level of significance. An odds ratio of 0.480 indicates MSEs with negative attitude about loan repayment period are 0.480 times less likely to access credit from formal financial institutions than those who do not. It means that opinion about loan repayment period is not majorly affecting the probability of MSEs Operators formal financial institutions. This result is consistent with previous studies by (Bhende 2003 and Wenner 2000). Formal credit institutions have rules and regulations that limit the time at which the borrower should repay the loan. If the respondents fail to repay on time they will be sent to the court or their property may be confiscated. Due to this reason individuals fear taking loans from formal credit sources and are discouraged from participating in credit market (Bhende, 2003 and Wenner, 2000).

Age of operator (OPRage): The variable entrepreneur's age has a positive and statistically significant effect on MSE's access to credit from formal financial institutions at 5\% level of significance. Taking Entrepreneur's age of greater than 40 as a reference, we can see that the odds ratio for entrepreneurs between the age of 31-35 is 
0.105 . This indicates that entrepreneurs between the ages of 31-35 are 0.105 times less likely to access credit from formal financial institutions than those with age of greater than 40 . This result is consistent with previous study of Anthony et al (2013) but contrary to the study of Sabopetji and Belete (2009). The personal financing preferences of entrepreneurs appear to change according to age and the age of the entrepreneur is a significant determinant of the risk of borrowing. This implies that as the age of an entrepreneur increases, so does his business experience, practical, wisdom and his income generating capacity (Swain, 2001). In addition, due to capability of the older entrepreneurs to accumulate assets which are used as collaterals, formal financial institutions perceive them as creditworthy. As a result, they are more likely to access credit from formal financial institutions than the younger entrepreneurs.

Educational level of the operator (OPReduc): Educational level of the MSE operators or managers has a positive and statistically significant effect on MSEs' access to credit from formal financial institutions at 5\% level of significance. Taking higher level of education as a reference (TVET/College and above) we can see that the odds ratios for no formal education is 0.055 . This indicates that compared to MSE operators or mangers who have attended TVET/College and above, those with no formal education are 0.055 times less likely to get credit from formal financial institutions at the given level of significance. This result is consistent with previous studies of (Omboi and Priscilla, 2011; Coleman, 2007; Charles, 2009) but contrary to (Tsehaye, 2013). Irwin and Scott (2010) also assert that firstly, more educated entrepreneurs have the ability to present positive financial information and strong business plans and they have the ability to maintain a better relationship with financial institutions compared to less educated entrepreneurs. Secondly, the educated entrepreneurs have the skills to manage the other functions of the business such as finance, marketing, human resources and these skills results to high performance of the business which helps those firms to access finance without any difficulty. The third reason stems from the supply side, where the bankers value higher education level of the owner/manager in the loan approval process as an important criterion (Irwin and Scott, 2010). We can therefore say that Level of education is a major factor that affects MSEs' access to credit from formal financial institutions. This probably is either because a higher education means that entrepreneurs are more articulate and more likely therefore to persuade the formal financial institutions that they have a viable proposition or because financial institutions value entrepreneurs with higher education.

Firm Size (ENTsize): Employment size is another factor that has a positive and significant effect on MSEs' access to credit from formal financial institutions at $1 \%$ level of significance. Taking MSEs with employment size of greater than 5 as a reference, the odds ratio for MSEs with employment size of less than 5 is 0.140 . This means that compared to MSEs with greater than 5 employees, MSEs with less than 5 employees are 0.140 times less likely to access credit from formal financial institutions. This result is consistent with previous studies of (Cassar, 2004; Gebru, 2009; Honhyan, 2009). A World Bank survey confirms that large firms everywhere generally have more access to bank credit than small firms (Cull et al., 2005). Formal sector credit is out of reach for smaller enterprises and compared to large firms, smaller firms face a relative disadvantage to raise finance from formal institutions such as banks because they are considered to have higher financial risk (Gebru, 2009). Small firms face with information opacity such as being unable to provide financial information. When the firm is small, most of the time it is owned and operated by the entrepreneur himself and there is no such legal requirement to regularly report financial information and many firms do not maintain audited financial accounts (Storey, 1994).

According to the survey, the variable Gender had no significant effect on access to credit from formal financial institutions. This implies that formal financial institutions do not set a difference in lending to MSE operators by gender and females are not different from males in accessing credit from formal financial institutions. Firm age did not have significant effect on firm's access to credit with mean age of 3.23years for those with no access and mean age of 3.63 years for those with access. This implies that contrary to other studies, operating period or age of the enterprise does not create a difference with respect to access to credit from formal financial institutions. Although there is a positive relationship between sector and access to credit, there is no statistically significant difference in access to credit from formal financial institutions between MSEs engaged in manufacturing sector and other sectors. This implies that financial institutions do not discriminate between sectors when giving loans. Besides, since the overall percentage of MSEs with fixed asset is low, the presence of tangible assets which is more often associated with the manufacturing sector in effect does not contribute to better access to credit of the manufacturing sector. Interest rate did not have significant effect on access to credit from formal financial institutions. The explanation could be that since the maximum amount of interest rate charged by the main microfinance institution in Gesuba Town is $10 \%$ and because there are MSEs which previously received credit without interest rate; it is not perceived as a barrier for access to credit.

\section{CONCLUSION AND RECOMMENDATION} 4.1 Conclusion

Access to finance is one of the key obstacles of MSEs not only when starting the business project but also when 
operating. Identifying the major determinants of access to finance is therefore quite crucial. The results of the binary logistics model indicate that MSEs run by operator above the age 40 years are 9.52 times more likely to access credit from formal financial institutions than those between the age of 31-35 years. The probability of access to credit from formal financial institutions also increased as the level of education increased with operator who has reached TVET/College being 18.18 times more likely to access credit from formal financial institutions than those with no formal education. MSEs who had fixed asset were 1.958 times more likely to access credit from formal financial institutions than those who did not. MSEs with higher employment size were also more likely to access credit from formal financial institutions with MSEs having more than 5 employees 7.14 times more likely to access credit from formal financial institutions compared to MSEs that have less than 5 employees. The attitude of MSE operators or managers towards lending procedures and loan repayment periods were also found to significantly affect their decision to apply for loan from formal financial institutions. MSE operators or managers with negative attitude about lending procedures and loan repayment period of formal financial institutions were 0.234 and 0.48 times less likely to access credit from formal financial institutions respectively than those who did not.

Taking the findings, the study concludes that the major source of startup finance and also working capital is own savings. The major source of credit for startup on the other hand is family and friends followed by microfinance and 'equb'. The major source of credit for working capital is also informal financial institutions. Age of the operator, educational level of the operator, possession of fixed asset, employment size of MSEs, perceptions about lending procedure and loan repayment period had statistically significant effects on access to credit from formal financial institutions. In contrast gender of the entrepreneur, firm age, sector and perception about interest rate had no effect on MSEs' access to credit from formal financial institutions.

\subsection{Recommendation}

There are various factors that affect access to finance of MSEs. Recognizing their heterogeneity and devising policies and support programs to alleviate these problems is quite important. Appropriate understanding of these factors is therefore important in order to solve financial needs of MSEs and help them prosper and achieve their objectives in creating employment and alleviating poverty. It will also help the government and nongovernmental organizations to formulate policies and strategies that work towards meeting the financial needs of MSEs. On the basis of the findings and conclusions reached, the following recommendations have been forwarded. The requirement for collateral is hampering many MSEs from taking loans and financing their business to promote growth and diversification of their enterprises. Considering that most operators in the MSEs sector do not have fixed asset, it is quite important to seek alternative means of guarantees such as strengthening the practice of using salaries of employed people as a guarantee. Lending procedure of financial institutions is one of the major factors that affect decision of MSE operators and owner managers to apply for loan. The government in collaboration with financial institutions should therefore work to solve this problem and ease lending procedure. Loan repayment period of financial institutions is also another factor hampering access to credit from formal financial institutions. Efforts should therefore be extended by formal financial institutions to extend loan repayment periods.

\section{REFERENCES}

- Abor J, Biekpe N. 2009. How do we explain the capital structure of SMEs in Sub Saharan Africa.Journal of Economic Studies 36(1):83-97

- Abor, J.2007. Industry classification and the capital structure of Ghanaian SMEs. Studies in Economics and Finance, 24(3):207-219.

- Abor, J., \&Biekpe, N. 2006.Small Business Financing Initiatives in Ghana.Problems and Perspectivesin Management, 4(3), 69-77.

- CSA (Central Statistics Agency), 2000. Demographic and Health survey.Centeral Statistics Agency. Addis Ababa, Ethiopia.

- CSA (Central Statistics Agency), 2008 'Summary and Statistical report of the 2007 population

- Cull R, Xu L, 2005. Institutions, ownership, and finance: the determinants of profit re-investment among Chinese firms. Journal of Finance and Economics. 77:117-46.

- Ethiopian Central Statistical Agency. 2011. Report on population size of Asella town. Addis Ababa

- Gedam M. 2010. The role of ACSI in addressing financial needs of women clients engaged in micro and small enterprises: the case of Bahr Dar branch. A Master's thesis.Addis Ababa University, Addis Ababa Ethiopia.

- Gitari, C. 2012. Factors Affecting Women Entrepreneurs' Financial Performance In Kenya: A Case of Ngara Market. School of Business, University of Nairobi.

- Green, A.2003. Credit Guarantee Schemes for Small Enterprises: An Effective Instrument to Promote Private Sector-Led Growth? SME Technical Working Paper No. 10.Vienna: UNIDO. 
- Gujarati, Damodar N. 1988. Basic Econometrics.Second Edition. McGraw-Hill BookCompany, New York. U.S.A.

- Habtamu Tefera, Aregawi Gebremichael and Nigus Abera. (2013). Growth Determinants of Micro and Small enterprise: evidence from Northern ethiopia. Journal of Economics and sustainable development, 4(9), 127-135.

- $\quad$ Klapper,S.F and Rajan, Z. 2006. Entry Regulation as a barrier to Entrepreneurship, Journal of Financial Economic, 82(3) pp: 8-51

- Mugenda, A. G., \&Mugenda, O. M., 2003; Research Methods, Quantitative and Qualitative Approaches, ACTS Press, Nairobi.

- Mulugeta Y. F. 2011. The Livelihoods Reality of Micro and Small Enterprise Operators: Evidences from Woreda One of Lideta Sub-city, Addis Ababa.Master's Thesis.Addis Ababa University, Ethiopia.

- Myers, S. C. \&Majluf, N. S. 1984, 'Corporate Financing and Investment Decisions When Firms Have Information That Investors do not Have', Journal of Financial Economics, June 187-221.

- Nalyanya, Charles N. 2012. An Investigation into Factors Affecting the Performance Of Small Scale Enterprises in ASAL areas Hola Town-Tana River District. Kenya.

- Odit, M. P., andGobardhun, Y. D. 2011. The Determinants of Financial Leverage of SME's in Mauritius. The International Business and Economics Research Journal,10(3), 113.

- $\quad$ Storey, D. J. 1994.Understanding the Small Business Sector.Thomson Learning Emea.

- Swain, 2001.Demand, Segmentation and Rationing in the rural credit Markets of Puri.Ph.D. diss. (Uppsala University).

- Trade and Industry Bureau statistical abstract report (2009), SNNPR,Hawasa

- Tsehaye G. 2013. Determinants of Credit Rationing of Small and MicroEnterprises: Case of Mekelle City, North Ethiopia. MSc Thesis Development Economics.Wageningen University.Wageningen, The Netherlands. Verheul, I., andThurik, R. (2001). Start-Up Capital: Does Gender Matter? Small Business Economics, 16(4),329-346.

- Vos, E., Yeh, A. J., Carter, S., andTagg, S. 2007. The Happy Story of Small Business Financing.Journal of Banking and Finance,31(9), 2648-2672.

- Wattanapruttipaisan, T. 2003. Four proposals for Improved Financing of SME Development. Indonesia: Jakarta, Asian Development Review, Vol. 20 No, 2.pp1-45.

- Wenner MD.2000. Group credit: A menace to improveinformation transfer and loan repayment performance. Journal of Development Studies, 32(2):263- 281.

- Wiklund, J. and D. Shepherd 2003. "Knowledge-based Resources, Entrepreneurial Orientation and Performance of Small and Medium Sized Businesses.” Strategic Management Journal,24, 1307-1314 